\title{
Crosslinking of dermal sheep collagen using hexamethylene diisocyanate
}

\author{
L. H. H. OLDE DAMINK, P. J. DIJKSTRA, M. J. A. VAN LUYN*, P. B. VAN \\ WACHEM*, P. NIEUWENHUIS*, J. FEIJEN \\ Department of Chemical Technology, University of Twente, P.O. Box 217, 7500 AE, \\ Enschede, The Netherlands \\ *Department of Histology and Cell Biology, University of Groningen, Ostersingel 69/2, 9713 \\ $E Z$, Groningen, The Netherlands
}

The use of hexamethylene diisocyanate (HMDIC) as a crosslinking agent for dermal sheep collagen (DSC) was studied. Because HMDIC is only slightly water soluble, a surfactant was used to obtain a clear and micellar crosslinking solution and to promote the penetration of HMDIC in the DSC matrix. Using optimized conditions treatment of non-crosslinked DSC (N-DSC) with HMDIC (H-DSC) increased the shrinkage temperature $\left(T_{\mathrm{s}}\right)$ of N-DSC from $56^{\circ} \mathrm{C}$ to $74^{\circ} \mathrm{C}$ for $\mathrm{H}$-DSC. A linear relation between the decrease in free amine group content and the increase in $T_{\mathrm{s}}$ was observed. Crosslinking with HMDIC did not influence the tensile strength of the N-DSC samples but increased the elongation at break from $141 \%$ to $163 \%$ and decreased the high-strain modulus from $26 \mathrm{MPa}$ to $16 \mathrm{MPa}$ for the H-DSC samples, respectively.

\section{Introduction}

Stabilization of collagen-based biomaterials either by physical or chemical methods is necessary in order to decrease the susceptibility towards enzymatic degradation. Only sufficiently stabilized materials will maintain the required mechanical properties and stability during the desired implantation period. Glutaraldehyde (GA) crosslinking is commonly used and accepted for the stabilization of collagen-based biomaterials [1]. However, more recently it has been reported that collagen stabilized by $\mathrm{GA}$ elicits toxic effects in vitro $[2,3]$. These effects have been related to the release of toxic GA (related) molecules from the material $[4,5]$. These GA (related) molecules may result from unreacted GA present in the samples or from hydrolytic or enzymatic degradation products [6].

Chvapil et al. [7] used the bifunctional reagent hexamethylene diisocyanate (HMDIC) as an alternative for GA crosslinking. Treatment of collagen-based biomaterials with HMDIC mainly involves the formation of crosslinks containing stable urea groups resulting from the reaction of isocyanate groups with amine groups [8]. It was shown that after subcutaneous implantation in rats of both GA and HMDIC crosslinked collagen sponges, only the HMDIC crosslinked sponges did not induce a cytotoxic reaction of the host tissue. This has been confirmed by recent studies on the in vitro cytotoxicity and in vivo behaviour of diisocyanate and glutaraldehyde crosslinked dermal sheep collagen $[9,10]$.

To our knowledge, no detailed studies have been reported in the literature in which the effects of cross- linking using HMDIC on the properties of collagenbased biomaterials is determined. In this study the effect of crosslinking of dermal sheep collagen (DSC) using HMDIC on the shrinkage temperature, the free amine group content and the mechanical properties is reported. A comparison with previously reported results using glutaraldehyde (GA) for the crosslinking of DSC is made [6].

\section{Materials and methods}

Dermal sheep collagen (DSC) was obtained from the Zuid-Nederlandse Zeemlederfabriek (Oosterhout, The Netherlands) and was prepared as reported previously [11]. The fibrous collagen network was washed four times with water, twice with acetone and twice with water, and was subsequently frozen and lyophilized to give non-crosslinked dermal sheep collagen (N-DSC).

2.1. Crosslinking of dermal sheep collagen In a typical experiment, N-DSC samples $(5 \times 5 \mathrm{~cm})$ weighing $1 \mathrm{~g}$ were crosslinked in $100 \mathrm{ml}$ of a phosphate buffer $\left(0.054 \mathrm{M} \mathrm{Na}_{2} \mathrm{HPO}_{4}, 0.013 \mathrm{M} \mathrm{NaH}_{2} \mathrm{PO}_{4}\right.$, $\mathrm{pH}$ 7.4) containing $1.5 \% \quad(\mathrm{w} / \mathrm{w})$ hexamethylene diisocyanate (HMDIC, z.S., Merck-Schuchardt, Hohenbrunn, FRG) and 1.0\% (w/w) Tween 80 (z.S., Merck-Schuchardt, Hohenbrunn, FRG) as a surfactant for $5 \mathrm{~h}$ at room temperature. During crosslinking the $\mathrm{pH}$ of the HMDIC solution was monitored and adjusted with $\mathrm{HCl}$ or $\mathrm{NaOH}$ if necessary. After crosslinking the HMDIC treated samples (H-DSC) were 
rinsed for $30 \mathrm{~min}$ by running tap water, washed twice for $30 \mathrm{~min}$ with $4 \mathrm{M} \mathrm{NaCl}$ and washed four times for $30 \mathrm{~min}$ with distilled water to remove unreacted HMDIC or surfactant before lyophilization.

To study the kinetics of the HMDIC crosslinking both the free amine group content and the $T_{\mathrm{s}}$ of $\mathrm{H}$-DSC samples were monitored for time periods upto $24 \mathrm{~h}$. The influence of the HMDIC concentration on the free amine group content and the $T_{\mathrm{s}}$ was determined by immersing N-DSC samples in buffer solutions ( $\mathrm{pH}$ 7.4) containing HMDIC concentrations of $0.1,0.5,1.0,1.5,2.0,3.0$ and $5.0 \%(\mathrm{w} / \mathrm{w})$, respectively. The free amine group content and the $T_{\mathrm{s}}$ as a function of the $\mathrm{pH}$ of the crosslinking solution were determined at $\mathrm{pH}$ values between 5.5 and $13\left(0.07 \mathrm{M} \mathrm{NaH} \mathrm{PO}_{4}\right.$ adjusted with $\mathrm{NaOH}$ ). The influence of the type of surfactant used during crosslinking on the free amine group content and the $T_{\mathrm{s}}$ was determined by using either Tween 20, Tween 60, Tween 80, Brij 35 (all z.S., Merck-Schuchardt, Hohenbrunn, FRG) or Emulvin W (Bayer, Leverkusen, BRD). The free amine group content and the $T_{\mathrm{s}}$ as a function of the concentration of the surfactant used were determined by varying the concentration of Tween 80 between 1 and $10 \%(w / w)$ and using a HMDIC concentration of $5 \%(\mathrm{w} / \mathrm{w})$.

Crosslinking of N-DSC with glutaraldehyde (GA) was performed by immersing $\mathrm{N}$-DSC samples $(5 \times 5 \mathrm{~cm})$ weighing $1 \mathrm{~g}$ in $100 \mathrm{ml}$ of a phosphate buffer $\left(0.054 \mathrm{M} \quad \mathrm{Na}_{2} \mathrm{HPO}_{4}, \quad 0.013 \mathrm{M} \quad \mathrm{NaH}_{2} \mathrm{PO}_{4}, \mathrm{pH}\right.$ 7.4) containing $0.5 \%(\mathrm{w} / \mathrm{w})$ purified $\mathrm{GA}$ for $1 \mathrm{~h}$ at room temperature to give G-DSC. After crosslinking the G-DSC samples were rinsed for $30 \mathrm{~min}$ by running tap water, washed twice for $30 \mathrm{~min}$ with $4 \mathrm{M} \mathrm{NaCl}$ and washed four times for $30 \mathrm{~min}$ with distilled water to hydrolyse any Schiff base entities and remove unreacted GA before lyophilization.

\subsection{Characterization}

The degree of crosslinking of the samples was related to the increase in shrinkage temperature $\left(T_{\mathrm{s}}\right)$ after crosslinking with either GA or HMDIC [12]. $T_{\mathrm{s}}$ values of crosslinked or non-crosslinked DSC samples immersed in water were determined as described previously [6]. The free amine group content of the samples was determined spectrophotometrically after reaction of the primary amine groups with 2,4,6-trinitrobenzene-sulfonic acid (TNBS) [6] and is expressed as the number of amine groups present per 1000 amino acids $(n / 1000)$. All measurements were performed in triplicate. Changes in $T_{\mathrm{s}}$ and free amine group content were always compared to matching non-crosslinked controls (sample size $5 \times 5 \mathrm{~cm}$ ).

\subsection{Mechanical properties}

Stress-strain curves of non-crosslinked and crosslinked DSC samples $(5 \times 5 \mathrm{~cm})$ were determined by uniaxial measurements using an Instron mechanical tester. Tensile test samples $(30.0 \times 6.0 \times 0.8 \mathrm{~mm})$ were cut using a blade knife and were hydrated for at least $30 \mathrm{~min}$ in phosphate buffered saline (PBS, 0.14 M $\mathrm{NaCl}, 0.01 \mathrm{M} \mathrm{Na}{ }_{2} \mathrm{PO}_{4}, 0.002 \mathrm{M} \mathrm{NaH}_{2} \mathrm{PO}_{4}, \mathrm{pH}$ 7.4,
NPBI, Emmercompascuum, the Netherlands) at room temperature. The tensile strength, the elongation at alignment, the elongation at break, the low-strain modulus and the high-strain modulus of the sample were calculated from five independent measurements. Because of variations in the mechanical properties of different parts of the sheep skin [13], the change in mechanical properties of crosslinked samples was only compared with the mechanical properties of matching non-crosslinked controls. Samples used to study the influence of crosslinking on the mechanical properties were always taken from the IUP/2 [14] sampling area parallel to the backbone and were either crosslinked with HMDIC or GA or kept as control.

\section{Results}

\subsection{Crosslinking}

In Fig. 1 the $T_{\mathrm{s}}$ and the free amine group content of the H-DSC samples as a function of crosslinking time are presented. For N-DSC samples a free amine group content of 33/1000 amino acid residues was found which is in good agreement with values reported in literature [15]. Reaction of N-DSC samples with HMDIC resulted in an increase in $T_{\mathrm{s}}$ and a decrease in free amine group content compared to N-DSC samples, indicating that crosslinking occurred. $T_{\mathrm{s}}$ and free amine group content reached plateau values of $71^{\circ} \mathrm{C}$ and $19 / 1000$ amino acid residues, respectively, after $5 \mathrm{~h}$ crosslinking.

The influence of the HMDIC concentration used during crosslinking on $T_{\mathrm{s}}$ and free amine group content is given in Fig. 2. Crosslinking of N-DSC samples for $5 \mathrm{~h}$ resulted in plateau values for $T_{\mathrm{s}}$ of $72^{\circ} \mathrm{C}$ and for free amine group content of 19/1000 amino acid residues at HMDIC concentrations higher than $1.5 \%$ $(w / w)$.

The $\mathrm{pH}$ of the crosslinking solution appeared to have a large effect on the crosslinking reaction (Fig. 3). Using a reaction time of $5 \mathrm{~h}$ and a HMDIC concentration of $1.5 \%(w / w)$ the crosslinking was most effective at a $\mathrm{pH}$ value of 9.5. At $\mathrm{pH}$ values lower than 8 an average $T_{\mathrm{s}}$ of $72{ }^{\circ} \mathrm{C}$ was found. Increasing the $\mathrm{pH}$ to 9.5 gave a slight increase in $T_{\mathrm{s}}$ to $74^{\circ} \mathrm{C}$ whereas the free amine group content decreased to $14 / 1000$ amino acid residues.

Increasing $\mathrm{pH}$ to 13 gave a sharp decrease in $T_{\mathrm{s}}$ values. At $\mathrm{pH}$ 13, HMDIC still reacts with amine groups, as is shown by the lower free amine group content of $22 / 1000$ amino acid residues compared to $\mathrm{N}$-DSC samples (33/1000 amino acid residues). However, crosslinking does not take place, as indicated by the low $T_{\mathrm{s}}$ values which are similar to non-crosslinked DSC samples.

The use of different surfactants during crosslinking of N-DSC samples with $1.5 \%$ (w/w) HMDIC for $5 \mathrm{~h}$ only resulted in minor differences in $T_{\mathrm{s}}$ as can be seen in Fig. 4. A $T_{\mathrm{s}}$ value of $72^{\circ} \mathrm{C}$ was found when $1.0 \%$ (w/w) Tween $20,60,80$ or Emulvin W were used, whereas for Brij 35 a value of $69^{\circ} \mathrm{C}$ was measured.

The influence of the concentration of surfactant on the $T_{\mathrm{s}}$ of the samples was studied by varying the concentration of Tween 80 between $1 \%(w / w)$ and 


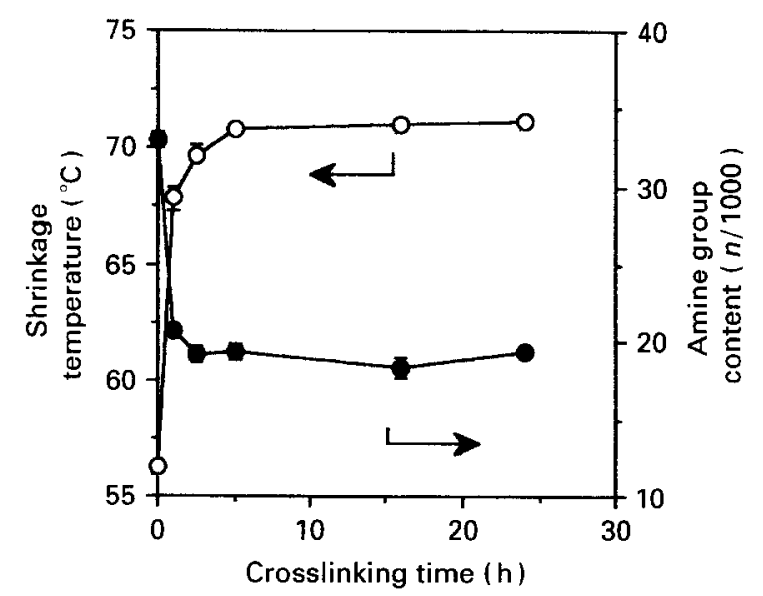

Figure 1 Shrinkage temperature $(O)$ and free amine group content (O) of H-DSC samples as a function of crosslinking time (RT, $\mathrm{pH}$ $7.4,1.0 \%$ (w/w) HMDIC, $1.0 \%(\mathrm{w} / \mathrm{w})$ Tween $80, n=3$ ).

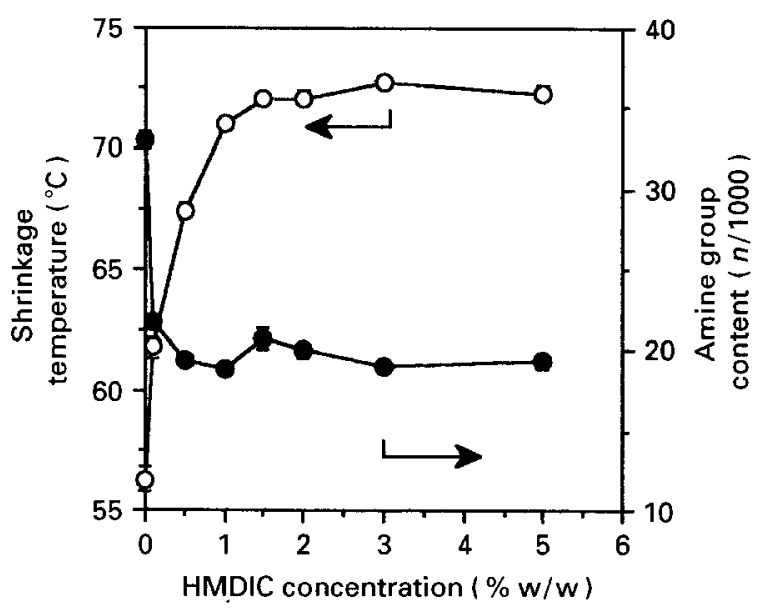

Figure 2 Shrinkage temperature $(O)$ and free amine group content (O) of H-DSC samples as a function of HMDIC concentration (RT, $5 \mathrm{~h}, \mathrm{pH} 7.4,1.0 \%(\mathrm{w} / \mathrm{w})$ Tween $80, n=3)$.

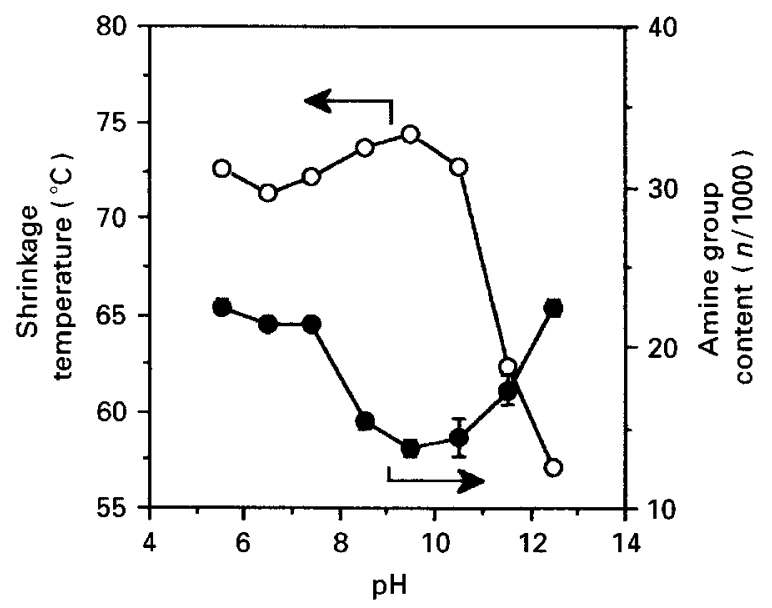

Figure 3 Shrinkage temperature $(\mathrm{O})$ and free amine group content (O) of H-DSC samples as a function of the $\mathrm{pH}(\mathrm{RT}, 5 \mathrm{~h}, 1.5 \%(\mathrm{w} / \mathrm{w})$ HMDIC, $1.0 \%$ (w/w) Tween $80, n=3$ ).

$10 \%(\mathrm{w} / \mathrm{w})$. During these experiments a HMDIC concentration of $5 \% \mathrm{w} / \mathrm{w}$ was used to amplify the possible effect of the concentration of surfactant on the degree of crosslinking. However, no effect on $T_{\mathrm{s}}$ values of the samples was found. At all surfactant concentrations a $T_{\mathrm{s}}$ of $72^{\circ} \mathrm{C}$ was observed.

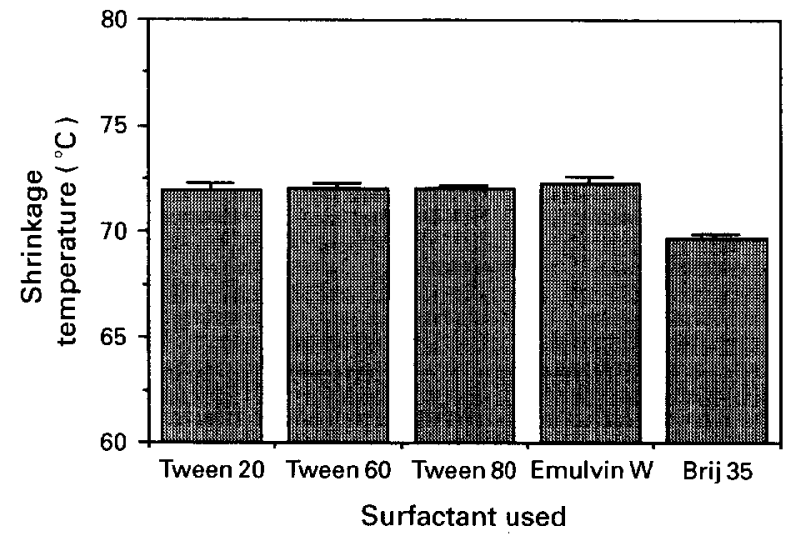

Figure 4 Shrinkage temperature of H-DSC samples as a function of

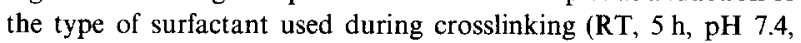
$1.5 \%(\mathrm{w} / \mathrm{w})$ HMDIC, $1.0 \%(\mathrm{w} / \mathrm{w})$ Tween $80, n=3$ ).

\subsection{Mechanical properties}

In Table I the mechanical properties of N-DSC, H-DSC and G-DSC samples are given. From stressstrain measurements of N-DSC samples [6] a tensile strength and elongation at alignment of $18.5 \mathrm{MPa}$ and $68 \%$, respectively, were determined. For both H-DSC and G-DSC samples no significant differences in tensile strength and elongation at alignment were observed compared to the N-DSC samples. Both the elongation at break and the low-strain modulus increased when N-DSC was crosslinked with either GA or HMDIC. The elongation at break increased from $141 \%$ for $\mathrm{N}$ DSC to $160 \%$ for both H-DSC and G-DSC, while the low-strain modulus increased from $2.0 \mathrm{MPa}$ for $\mathrm{N}$ DSC to 3.5 MPa for H-DSC and 4.6 MPa for G-DSC. Compared to N-DSC samples, the high-strain modulus decreased upon crosslinking, from $26.3 \mathrm{MPa}$ to $16 \mathrm{MPa}$ for both H-DSC and G-DSC samples.

\section{Discussion}

Collagen-based biomaterials are frequently crosslinked with glutaraldehyde (GA) to control the enzymatic degradation rate of the materials during implantation [1]. Recently it was reported that GA-crosslinked collagen-based biomaterials were cytotoxic $[2,3]$, probably due to the release of GA (related) molecules $[4,5]$. This release can be due to the presence of unreacted GA or the hydrolytic or enzymatic degradation of part of the crosslinks introduced during GA treatment.

To overcome these problems the use of hexamethylene diisocyanate (HMDIC) was suggested as an alternative crosslinking agent for GA [7]. As with GA, crosslinking of collagen with HMDIC involves the bridging of two adjacent free amine groups. In a first step, reaction of an isocyanate group (II) with a lysine or hydroxylysine amine group (I) occurs resulting in the formation of a urea bond (III) as is shown in Scheme 1. Thereafter crosslinking becomes possible by reaction of the pendant-free isocyanate group with a second free amine group (IV). Crosslinking may also involve reactions of the isocyanate groups with amide bonds present in the polypeptide chain (V) although this reaction is much slower [8] than the reaction of the 
TABLE I Mechanical properties ${ }^{\mathrm{a}, \mathrm{b}}$ of N-DSC, H-DSC and G-DSC

\begin{tabular}{llllll}
\hline Sample & $\begin{array}{l}\text { Tensile } \\
\text { strength } \\
(\mathrm{MPa})\end{array}$ & $\begin{array}{l}\text { Elongation at } \\
\text { alignment } \\
(\%)\end{array}$ & $\begin{array}{l}\text { Elongation at } \\
\text { beak } \\
(\%)\end{array}$ & $\begin{array}{l}\text { Low-strain } \\
\text { modulus } \\
(\mathrm{MPa})\end{array}$ & $\begin{array}{l}\text { High-strain } \\
\text { modulus } \\
(\mathrm{MPa})\end{array}$ \\
\hline N-DSC & $18.5 \pm 1.3$ & $68 \pm 6$ & $141 \pm 7$ & $2.0 \pm 0.3$ & $26.3 \pm 3.2$ \\
H-DSC $^{\mathrm{d}}$ & $16.5 \pm 1.6$ & $63 \pm 7$ & $163 \pm 5$ & $3.5 \pm 0.4$ & $15.7 \pm 0.9$ \\
G-DSC $^{\mathrm{c}}$ & $17.8 \pm 1.2$ & $61 \pm 3$ & $160 \pm 5$ & $4.6 \pm 0.7$ & $16.3 \pm 1.1$ \\
\hline
\end{tabular}

all mechanical properties were measured five times and are given as mean \pm standard deviation

${ }^{\mathrm{b}}$ The $T_{\mathrm{s}}$ and free amine group content of the collagen used to determine the mechanical properties were $56.0 \pm 0.3$ and $33.2 \pm 0.3$ for NDSC, $73.8 \pm 0.3$ and $16.9 \pm 0.4$ for HDSC, and $77.7 \pm 0.3$ and $9.9 \pm 0.3$ for GDSC, respectively.

${ }^{c}$ Non-crosslinked DSCN

d Hexamethylene diisocyanate crosslinked DSC. N-DSC samples were crosslinked in phosphate buffer (pH 9.5) containing $1.5 \%$ (w/w) HMDIC and $1.0 \%(\mathrm{w} / \mathrm{w})$ Tween 80 for $5 \mathrm{~h}$.

${ }^{\bullet}$ Glutaraldehyde crosslinked DSC.

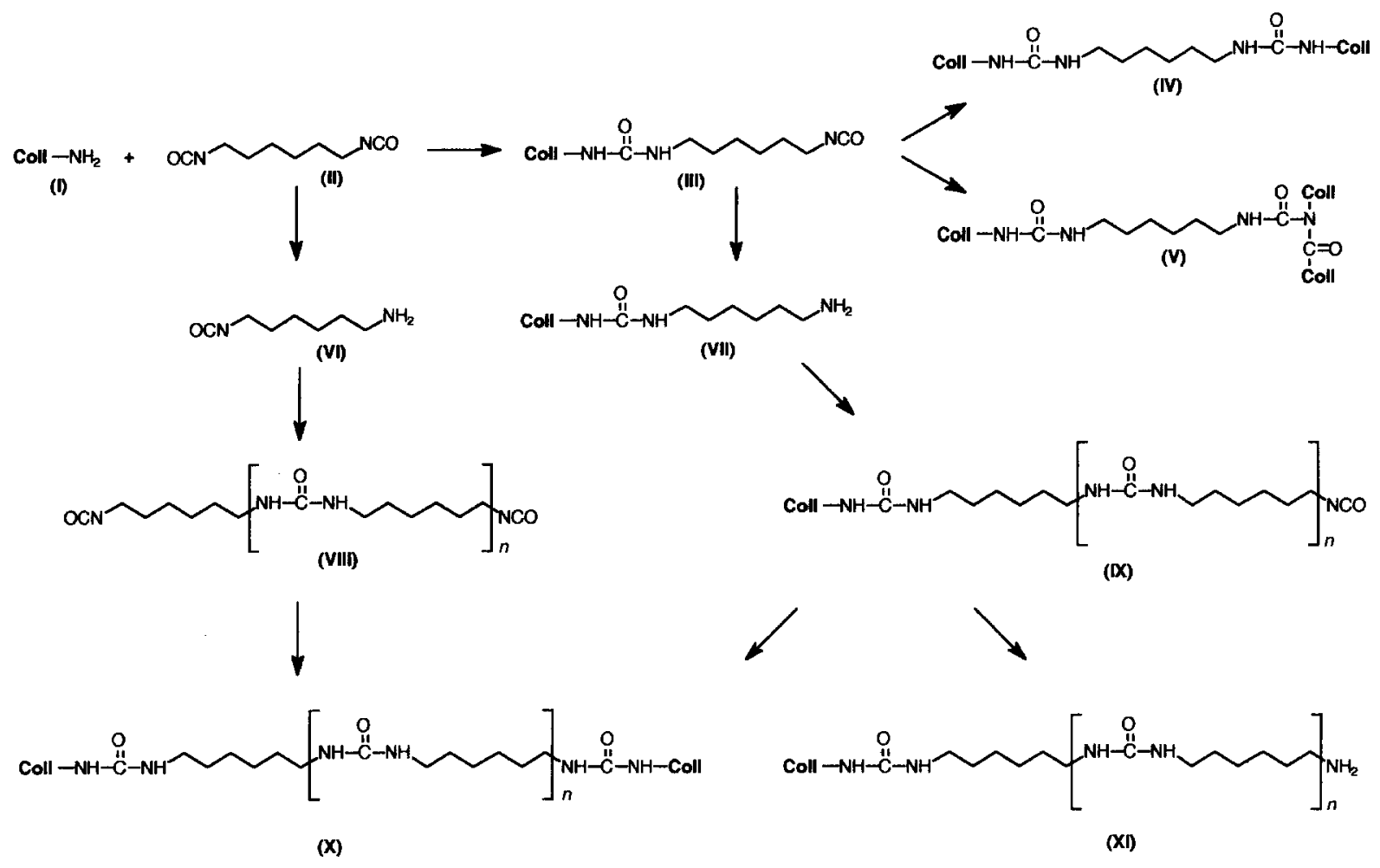

Scheme 1.

isocyanate group with a primary amine. Oligomeric crosslinks can be formed when (pendant) free isocyanate groups (II and III) are hydrolysed to give a (pendant) free amine group (VI and VII). Reaction of the newly formed amine group with HMDIC (VIII and IX) followed by reactions with an amine group of collagen (X and $\mathrm{XI}$ ) will give an extended crosslink. All reactions described for the crosslinking with HMDIC involve the formation of urea bonds.

The increase in shrinkage temperature $\left(T_{\mathrm{s}}\right)$ and the decrease in free amine group content of HMDIC crosslinked DSC samples was monitored to optimize the degree of crosslinking. In preliminary experiments it was found that a surfactant had to be used during crosslinking because HMDIC is only slightly soluble in a buffer solution. In the presence of a surfactant the bulk of the HMDIC molecules are present within micelles. It was observed that after addition of the surfactant to a mixture of HMDIC and buffer, the HMDIC phase disappeared and a clear micellar sys- tem was obtained. The crosslinking solution promotes the penetration of HMDIC in the DSC matrix. Furthermore, since the concentration of water in the micelles is low the rate of hydrolysis of the isocyanate groups during crosslinking is decreased.

Previously we reported that treatment of dermal sheep collagen (DSC) with GA (G-DSC) using optimized conditions increased the $T_{\mathrm{s}}$ of the non-crosslinked DSC samples (N-DSC) from $56^{\circ} \mathrm{C}$ to $78^{\circ} \mathrm{C}$ for the G-DSC samples [6]. In the study reported here, crosslinking of $\mathrm{N}-\mathrm{DSC}$ samples with HMDIC using optimized conditions, i.e. $1.5 \%(w / w)$ HMDIC solution containing $1.0 \%(\mathrm{w} / \mathrm{w})$ Tween 80 for $5 \mathrm{~h}$ at $\mathrm{pH}$ 9.5 , increased $T_{\mathrm{s}}$ from $56^{\circ} \mathrm{C}$ to $74^{\circ} \mathrm{C}$ for the H-DSC samples. This suggests that crosslinking with GA results in materials with a higher degree of crosslinking than HMDIC-crosslinked materials. However, care has to be taken when the degree of crosslinking of samples crosslinked with different reagents is directly related to their $T_{s}$ values. 
The $T_{\mathrm{s}}$ of collagen-based materials depends on the degree of swelling of the material [12]. Since crosslinking decreases the degree of swelling, crosslinked samples will have a higher $T_{\mathrm{s}}$ value compared to non-crosslinked samples. However, the thermal stability and chemical structure of the crosslinks introduced may also influence the degree of swelling of the material. While crosslinking of DSC with GA may involve the formation of aliphatic or quaternary pyridinium type crosslinks, crosslinking with HMDIC will result in the introduction of aliphatic chains containing urea bonds. The differences between the types of crosslinks introduced can have an effect on the degree of swelling of the materials and thus on the $T_{\mathrm{s}}$ values of the materials.

Although both HMDIC and GA crosslinking involve reactions with the free amine groups of the polypeptide chains, the decrease in free amine group content during crosslinking is different for both reagents. It has been observed that for GA crosslinking up to a $T_{\mathrm{s}}$ value of $78^{\circ} \mathrm{C}$ and a free amine group content of 16 per 1000 amino acid residues, a linear relationship was found between the decrease in free amine group content and the increase in $T_{\mathrm{s}}[6]$. Reaction of GA with the remaining free amine groups was still possible after the maximum $T_{\mathrm{s}}$ value was reached. This finally resulted in reaction of about 27 of the 33 free amine groups present per 1000 amino acid residues. These latter reactions obviously did not lead to the formation of additional crosslinks since no further increase in $T_{\mathrm{s}}$ was observed. As can be seen in Fig. 5 , a linear relationship was found over the entire range of $T_{\mathrm{s}}$ values up to the maximum achievable value of $74^{\circ} \mathrm{C}$ for HMDIC crosslinking. It appeared that only 17 of the 33 free amine groups present per 1000 amino acid residues reacted upon crosslinking.

Pendant molecules (VII and XII) formed during crosslinking with HMDIC contain free amine groups after hydrolysis of the free isocyanate groups. These free amine groups may react with TNBS in the determination of the primary amine group content. Therefore, the formation of pendant molecules in the case of HMDIC crosslinking will not result in a decrease in free amine group content. This may give an explanation for the observed linear relation between the decrease in free amine group content and the increase in $T_{\mathrm{S}}$ independent of the formation of pendant groups.

Differences in the solubility of HMDIC and GA are expected to account for the differences observed in the degree of crosslinking of the resulting materials. While GA is water soluble and is known to penetrate efficiently into the DSC matrix resulting in both interand intramolecular crosslinking [16, 17], HMDIC is only slightly water soluble. Although a surfactant was used to improve the penetration of HMDIC into the DSC matrix, a similar penetration into the DSC matrix as observed for GA may not be achieved.

If HMDIC is less efficient in penetrating into the DSC matrix, non-homogeneously crosslinked materials may be obtained. However, during all $T_{\mathrm{s}}$ measurements the transition of the triple-helix to the random coil configuration was sharp and essentially complete within a temperature interval of $1-2{ }^{\circ} \mathrm{C}$ indicating

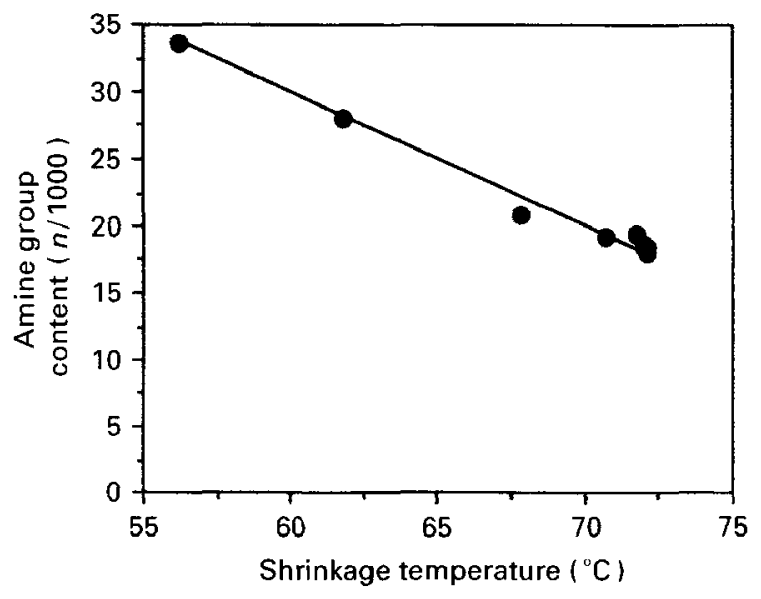

Figure 5 Free amine group content as a function of shrinkage temperature during crosslinking of DSC with HMDIC.

that crosslinks are homogeneously distributed in the H-DSC samples [18-20].

As discussed above crosslinking of DSC samples with HMDIC may also involve the reaction of isocyanate groups with amide bonds present in the polypeptide chains. An increase in $T_{\mathrm{s}}$ should be observed without a decrease in free amine group content. This would be expected especially at high degrees of crosslinking when significant amounts of free amine groups have already reacted. However, the linear relationship between the decrease in free amine group content and the increase in $T_{\mathrm{s}}$ (Fig. 5) suggests that these reactions do not contribute significantly to the increase in degree of crosslinking.

The mechanical properties of fibrous collagens like DSC depend not only on the mechanical properties of the fibre bundles, which are highly structured aggregates of fibres and fibrils, also the spatial arrangement of the fibre bundles and the interweaving of fibres from one bundle to another influence the mechanical properties of the material. No change in tensile strength and a decrease in high-strain modulus was observed when N-DSC samples were crosslinked with either GA or HMDIC (Table I). Furthermore, the observed mechanical properties of the G-DSC and H-DSC samples are identical, showing that the extent of the crosslinking reactions and the structure of the crosslinks introduced within the fibres do not influence the mechanical properties of the DSC matrix. This is consistent with previously reported results in which it was found that the degree of crosslinking of G-DSC samples does not influence the mechanical properties of the material [6].

\section{Conclusions}

Reaction of hexamethylene diisocyanate (HMDIC) with dermal sheep collagen (DSC) (N-DSC) resulted in materials with an increased shrinkage temperature $\left(T_{\mathrm{s}}\right)$ indicating that crosslinking occurred. Because HMDIC is only slightly water soluble a surfactant had to be used during crosslinking to promote the reaction of HMDIC with the free amine groups present in the polypeptide chains. A linear relation between the decrease in free amine group content and the increase in 
$T_{\mathrm{s}}$ was observed for the crosslinking. The influence of crosslinking on the mechanical properties of HMDIC crosslinked DSC samples revealed that crosslinks were introduced within fibres rather than in between fibres.

\section{References}

1. M. E. NIMNI, D. T. CHEUNG, B. STRATES, M KODA MA and K. SKEIK H, J. Biomed. Mater. Res. 21 (1987) $741-771$.

2. E. EYBEL, A. GRIESMACHER, M. GRIMM and E. WOLNER, ibid. 23 (1989) 1355-1365.

3. K. B. HEY, C. M. LACHS, M. J. RAXWORTHY and E. J. WOOD, Biotechnol. Appl. Biochem. 12 (1990) 85-93.

4. D. P. SPEER, M. CHVAPIL, C. D. ESKELSON and J. ULREICH, J. Biomed. Mater. Res. 14 (1980) 753-764.

5. L. L. H. HUANG-LEE, D. T. CHEUNG and M. E. NIMNI, ibid. 24 (1990) 1185-1201.

6. L. H. H. OLDE DAMINK P. J. DIJKSTRA. M. J. A. VAN LUYN, P. B. VAN WACHEM, P. NIEUWENHUIS and J. FEIJEN. J. Mater. Sci. Mater. Med.

7. M. CHVAPIL, D. SPEER, W. MORA and C. ESKELSON. J. Surg. Res., 35 (1983) 402-409.

8. H. TRÄUBEL, Das Leder 11 (1977) 150-154.

9. P. B. VAN WACHEM, M. J. A. VAN LUYN, L. H. H. OLDE DAMINK. P. J. DIJKSTRA. J. FEIJEN and P. NIEUWENHUIS, Int. J. Artif. Organs 17 (1994) 230-239.
10. M. J. A. VAN LUYN, P. B. VAN WACHEM, L. H. H. OLDE DAMINK, P. J. DIJKSTRA, J. FEIJEN and P. NIEUWENHUIS, Biomaterials 13 (1993) 1017-1024.

11. T. M. VAN GULIK and P. J. K LOPPER, Neth. J. Surg. 39(3) (1987) 90-94.

12. P. I. FLORY and R. R. GARRETT, J. Amer. Chem. Soc. 80 (1958) 4836-4845

13. A. VOS and P. J. VAN VLIMMEREN, J. Sac. Leather Technol. Chem. 57 (1973) 93-98.

14. SOC. LEATHER TR. CHEM., J. Soc. Leather Trades' Chemists 44 (1960).

15. P. NEDKOV, R. GLANVILLE, I. GOSHEV and K. KÜHN, Leder 34(4) (1983) 54-58.

16. D. T. CHEUNG and M. E. NIMNI, Conn. Tissue Res. 10 (1982) 201-216.

17. D. T. CHEUNG, N. PERELMAN, E. C. KO and M. E. NIMNI, ibid. 13 (1985) 109-115.

18. P. L. PRIVALOV, in "Advances in protein chemistry", edited by C. B. Anfinsen, J. T. Edsall and F. M. Richards (Academic Press, New York, 1982).

19. T. HAY ASHI and Y. NAGAI, J. Biochem. 73 (1973) 999-1006.

20. E. HEIDEMANN, J. Soc. Leather Technol. Chem. 66 (1982) $21-29$.

Recieved 11 December 1993

and accepted 29 December 1994 